\title{
Medidas de aseguramiento y reforma penal: una perspectiva desde los derechos humanos
}

\author{
RAÚL PLASCENCIA VILLANUEVA*
}

\begin{abstract}
SUMARIO: I. NOCIÓN RESPECTO DE LAS MEDIDAS DE ASEGURAMIENTO.II. DERECHOS FUNDAMENTALES Y MEDIDAS RESTRICTIVAS.- III. CLASIFICACIÓN DE LAS MEDIDAS DE ASEGURAMIENTO.- IV. DERECHO A LA LIBERTADY ASEGURAMIENTODEPERSONAS, ASÍCOMOLAINTROMISIÓNDOMICILIARIA.
\end{abstract}

I. NOCIÓN RESPECTO DE LAS MEDIDAS DE ASEGURAMIENTO

Daremos inicio a la explicación del presente apartado señalando que existe una diversidad terminológica en torno a las medidas de aseguramiento ${ }^{1}$. Por una parte, Carnelutti las denomina proveimientos cautelares; Chiovenda, medidas de conservación o cautelares²; Podetti, por su parte, utiliza el término de providencias de naturaleza cautelar; para De la Plaza son medidas provisionales de cautela; de otro lado, Pallares refiere que son las medidas preventivas de seguridad, y, por último, Calamandrei señala que son las providencias cautelares o precautorias.

Atentos a lo anterior, podemos decir que la presente investigación centra su atención no en la diversidad de términos que se han utilizado para referir ciertas actividades, sino más bien en los fines que persigue el derecho al utilizar dichas figuras jurídicas.

La doctrina ha distinguido, principalmente, dos fines de las medidas de aseguramiento. El primero está enfocado en una fase previa al proceso que se circunscribe a la investigación de los delitos, en la que el objetivo de dichas medidas será asegurar el proceso de conocimiento. El segundo enfoca las medidas de aseguramiento como garantía de la ejecución penal ${ }^{3}$.

Si tomamos como punto de partida la finalidad que persiguen las medidas de seguridad, podemos enunciar algunas de las definiciones que se han proporcionado en torno a estas.

* Es presidente de la Comisión Nacional de Derechos Humanos en México.

1 De acuerdo con el Diccionario de la Lengua Española, el término «asegurar» tiene múltiples acepciones, como: «1. tr. Dejar firme y seguro; establecer, fijar sólidamente. 2. tr. Poner a alguien en condiciones que le imposibiliten la huida o la defensa. 3. tr. Librar de cuidado o temor; tranquilizar, infundir confianza. U. t. c. Prnl. 4. tr. Dejar seguro de la realidad o certeza de algo. 5. tr. Afirmar la certeza de lo que se refiere. U. t. c. Prnl. 6. tr. Preservar o resguardar de daño a alguien o algo; defenderlo e impedir que pase a poder de otra persona U. t. c. Prnl. 7. tr. Dar firmeza o seguridad, con hipoteca o prenda que haga cierto el cumplimiento de una obligación". Todas y cada una de esas situaciones nos proporcionan la idea de confianza, protección y seguridad, fines primordiales de todo Estado de derecho.

2 ChIOvendA, José. Principios de derecho procesal civil. Madrid: Editorial Reus S.A., 1992, p. 260.

3 Roxin, Claus. Derecho procesal penal. Vigésimo quinta edición. Buenos Aires: Editores del Puerto, 2000, p. 250. 
Para Fix Zamudio son «los instrumentos que puede decretar el juzgador, a solicitud de las partes o de oficio, para conservar la materia del litigio, así como para evitar un grave e irreparable daño a las mismas partes o a la sociedad, con motivo de la tramitación de un proceso» ${ }^{4}$.

Otro concepto que proporciona la doctrina es al que alude José Ovalle Favela, el que señala que las «acciones cautelares son aquellas por las que la parte actora solicita al juzgador una resolución para que se proteja, de manera provisional y hasta en tanto se dicte la sentencia definitiva en el proceso de conocimiento, a las personas, los bienes o los derechos que serán objeto de este último» ${ }^{5}$.

José Becerra Bautista, por su parte, señala que «el legislador se ha preocupado porque la tutela jurídica que puede obtenerse mediante el ejercicio de la función jurisdiccional no llegue demasiado tarde, y ha establecido procedimientos cautelares, cuya naturaleza provisional está destinada a hacer posible la actuación sucesiva y eventual de las tutelas definitivas típicas» ${ }^{6}$.

De otro lado, Podetti explica las medidas cautelares a través de una frase de Fiarén Guillén, en la que señala que son el «instrumento del instrumento». Así, alude al carácter realizativo del proceso y resalta que las medidas tienden a asegurar tal realización?

\section{DERECHOS FUNDAMENTALES Y MEDIDAS RESTRICTIVAS}

La adopción de medidas de aseguramiento tiene como efecto inmediato la injerencia en los derechos fundamentales protegidos por la Constitución Política de los Estados Unidos Mexicanos (CPEUM); las que deberán ajustares a lo previsto en los artículos 14 y 16 . Como bien lo establecen dichos preceptos, nadie podrá ser privado de sus derechos sino mediante juicio seguido ante los tribunales previamente establecidos, en el que se cumplan las formalidades especiales del procedimiento. Esto acompaña la prohibición absoluta, para la autoridad, de realizar actos de molestia sin que cumpla con los requisitos de mandamiento escrito de autoridad competente, y que funde y motive las causas legales del procedimiento.

La injerencia de las medidas cautelares se da en diversos ámbitos. Uno de ellos es el espacio de liberad personal, que se ve afectado por las órdenes de conducción coactiva, detención, prisión preventiva, encarcelamiento para la realización del juicio oral, internación en hospital psiquiátrico para examinar el estado de salud mental, registro de la persona, realización de radiografías y privación provisional del permiso de conducir;

4 FIX ZAMUDIO, Héctor. «Medidas cautelares». En Diccionario Jurídico Mexicano. México: PorrúaUNAM, 1977, t. I-O, p. 2091.

5 Ovalle FaVela, José. Teoría general del proceso. Quinta edición. México: Oxford University Press, 2001, p. 166.

6 BeCERRA BAUtISTA, José. El proceso civil en México. Décimo tercera edición. México: Porrúa, 1990, p. 439.

7 PODETTI, J. Ramiro. Tratado de las medidas cautelares. Buenos Aires: Ediar, 1969, p. 15. 
situaciones que observamos constantemente en la práctica cotidiana del desempeño de nuestra labor.

Otro de los bienes jurídicos tutelados por nuestro marco normativo es el relativo a la integridad corporal, la que, en diversas ocasiones, se ve afectada por el dictado de diversas medidas de aseguramiento, como la extracción de pruebas de sangre, la práctica de encefalogramas y otros estudios de laboratorio.

La afectación que pueden sufrir las personas en torno a sus bienes son múltiples, como: el aseguramiento judicial de objetos (el secuestro); la injerencia en el domicilio, en particular, el registro de lugares (registro domiciliario) en los que la persona se desenvuelve; la vigilancia acústica; la injerencia en el secreto postal, epistolar y de las comunicaciones a distancia, y el de la prohibición provisional de prácticas profesionales.

Otro de los derechos que se ve sistemáticamente vulnerado, por la injerencia de las autoridades en el momento en el que dictan las medidas cautelares, es el de la autodeterminación informativa. Este consiste, principalmente, de la búsqueda en redes, bases de datos, comparación de datos, empleo de medios técnicos, empleo de agentes encubiertos, así como de los nuevos métodos de pesquisa e intervención procesal penal en servicios de video de multimedios ${ }^{8}$.

\section{CLASIFICACIÓN DE LAS MEDIDAS DE ASEGURAMIENTO}

Con el objeto de hacer efectivas las decisiones tomadas por los funcionarios judiciales y cumplir con los fines procesales de determinadas personas o la disponibilidad de algunas cosas durante el trámite, la ley le otorga mecanismos especiales al funcionario judicial, que logran lo que en la teoría general del proceso se denomina la «coerción procesal» ${ }^{9}$.

Existen diversas clasificaciones de las medidas coercitivas, y Clariá Olmedo ${ }^{10}$ las clasifica en atención a la restricción que se hace de los derechos personales o patrimoniales impuesta en la realización penal, con la finalidad de obtener o asegurar los fines del proceso, el esclarecimiento de la verdad histórica y la aplicación de la ley sustantiva.

Sobre la base de esta clasificación, Vázquez Rossi ${ }^{11}$ destaca diversas características de las medidas de coerción. En la primera, el autor distingue el carácter instrumental accesorio al proceso, ya que sin él no podría subsistir. La segunda es el propósito asegurativo, el que se alcanza al impedir que se dé una variación en las condiciones de hecho que

8 ROXIN. Derecho procesal penal. Ob. cit, p. 250.

9 MANZINI, Vicenio. Tratado de derecho procesal penal. Tomo III. Venezuela: Ed. de Cultura Jurídica, 1987, p. 553. Es importante señalar que dicha coerción procesal se divide en personal y real.

10 CAFFERATA NORES, José Ignacio. Medidas de coerción en el proceso penal. Córdoba: Lerner, 1983.

11 VÁZQUEZ Rossı, Jorge Eduardo. Derecho procesal penal (la realización penal). Santa Fe: Rubinzal Culzoni Editores, 2004, pp. 242-244.

MEDIDAS DE

ASEGURAMIENTO

Y REFORMA

PENAL: UNA

PERSPECTIVA

DESDE LOS

DERECHOS

HUMANOS 
obstaculicen la aplicación del derecho. Otra característica es que deben de guardar una relación directa con lo que se pretende asegurar cuando son proporcionadas.

Cabe señalar, también, que dichas medidas son necesarias. La siguiente característica se refiere a la idoneidad, es decir, deben servir al objetivo para el que son dictadas. Es necesario, además, que sean verosímiles y que guarden relación con el fondo del asunto. También es posible señalar que son de interpretación restrictiva; las autoridades deben ceñirse a la norma en el momento en que las aplican, ya que existen procedimientos bien determinados sobre su procedencia y aplicación. Por último, son judiciales: los órganos jurisdiccionales competentes son los únicos que las pueden dictar.

En lo que se refiere a la coerción procesal, la doctrina distingue dos tipos: la primera se denomina coerción personal y va en función de los sujetos que se encuentren en el procedimiento. La segunda es la coerción real ${ }^{12}$, que atiende los bienes vinculados al juicio.

\section{1. Respecto de las personas}

La coerción personal procesal es «una limitación más o menos intensa sobre la libertad física de una persona con una finalidad procesal penal» ${ }^{13}$.

En términos generales, podemos señalar que la coerción personal se aplica para reprimir los actos contrarios a la disciplina procesal y con el objetivo fundamental de evitar conductas contrarias a la disciplina del proceso penal.

\section{III.1.1. Afectación a la integridad corporal. Medida de identificación}

La medida de identificación a la que aludiremos en este apartado es la relativa a los exámenes corporales del sujeto imputado, que sirven como medio de prueba para acreditar una situación de carácter relevante en el curso de un procedimiento. Un ejemplo de esto lo tenemos en los exámenes de sangre, que sirven para determinar el contenido de alcohol que ha ingerido un sujeto, y que consisten en analizar el cuerpo del imputado. Claus Roxin distingue entre los exámenes corporales y los registros corporales al señalar que, mientras los primeros aluden a los procesos orgánicos en el individuo, los segundos se limitan a buscar «objetos en la superficie corporal o en las cavidades u orificios corporales naturales» ${ }^{14}$.

Los exámenes de sangre no son los únicos que se practican, existen otros como la punción lumbar y el test de alcohol. Es necesario enfatizar la obligación que se le impone al imputado de tolerar de forma pasiva el 
examen, situación que incide de forma directa en la esfera jurídica de este. Por lo tanto, la actividad de los órganos encargados de la seguridad pública debería encontrarse perfectamente acotada, con el objetivo de tutelar mejor los derechos de todos los mexicanos, pues se ha observado, particularmente en el Distrito Federal, la proliferación de prácticas de esta naturaleza. Por ejemplo, el denominado «alcoholímetro» que, es preciso señalar, la Policía no puede obligar a ninguna persona a usar para someterla a un test de alcohol, pues soplar es considerado una acción.

Otra de las prácticas que han sido instauradas por los cuerpos encargados de la investigación de los delitos a nivel mundial es la del suministro coactivo de vomitivos, que tiene como finalidad el analizar la posible ingesta de cocaína. Esta práctica es una injerencia arbitraria en la integridad corporal del individuo, pues, cabe aclarar, contraviene el principio de la pasividad, ya que el vomito puede ser considerado como una acción activa.

La proliferación de las prácticas antes aludidas, en muchas ocasiones, incumple lo previsto por el artículo 16, párrafo primero, de la CPEUM. $\mathrm{Al}$ no ser dictadas por las autoridades competentes, incumplen con los requisitos de fundamentación y motivación, así como con el artículo 4 del mismo ordenamiento. Al poner en peligro la salud, se conduce a una negación absoluta del valor probatorio de dichos exámenes.

Otro aspecto que ha cobrado gran relevancia en la actualidad es el de los análisis genéticos, los que únicamente pueden llevarse acabo mediante una orden judicial escrita y en la que se indique el perito a quien se encarga el análisis.

\section{1. 2. A la libertad de ejercer actividad, oficio o profesión}

La inhabilitación provisional de ejercer la profesión es un aspecto de vital importancia, ya que es un problema de naturaleza compleja. Por una parte, atañe al individuo, pero también trasciende a la familia y, por último, a la sociedad. En lo que respecta al individuo, le impone la prohibición de dedicarse a su profesión u oficio, tal vez el único medio de subsistencia de su familia. Es necesario preguntarse si la persona a la que se inhabilita es, en efecto, el único sustento económico de ella que, de ser cierto, acarrearía un grave daño económico. En lo que respecta a la sociedad, esta está interesada en que las personas ejerzan su oficio o profesión con los conocimientos necesarios para realizarlos, y que se encuentren facultadas por la legislación nacional.

Es importante señalar que la inhabilitación provisional queda al arbitrio del juez, quien tendrá que valorar todas las circunstancias aludidas y ponderará a la luz del derecho fundamental de ejercer libremente la profesión, industria o comercio, consagrados en el artículo 5 de la CPEUM. También considerará el peligro probable del imputado y las

MEDIDAS DE ASEGURAMIENTO Y REFORMA

PENAL: UNA PERSPECTIVA DESDE LOS DERECHOS HUMANOS 
consecuencias que tendría para este la inhabilitación de ejercer la profesión ${ }^{15}$.

\section{1. 3. Injerencia en la vida privada, intervención de comunicaciones}

El artículo 16, párrafo noveno, de la CPEUM, establece la inviolabilidad de las comunicaciones privadas. De conformidad con este, podemos señalar que los servidores públicos están prohibidos de llevar acabo injerencias arbitrarias en las comunicaciones privadas si no se cumplen los requisitos consagrados en el citado numeral de la Constitución, como que solo la autoridad judicial federal, a petición de la autoridad federal que faculte la ley o del titular del Ministerio Público de la entidad federativa correspondiente, podrá autorizar la intervención de cualquier comunicación privada. Para ello, la autoridad competente, por escrito, deberá fundar y motivar las causas legales de la solicitud y expresar, además, el tipo de intervención, los sujetos de la misma y su duración. La autoridad judicial federal no podrá otorgar estas autorizaciones cuando se trate de materias de carácter electoral, fiscal, mercantil, civil, laboral o administrativo, ni en el caso de las comunicaciones del detenido con su defensor.

Con respecto a la intervención de las comunicaciones se pueden señalar múltiples hipótesis, una de ellas vinculada al uso de los teléfonos. Puesto que las vertiginosas trasformaciones en la sociedad, y los avances en la física y la electrónica, han multiplicado de manera exponencial el número de usuarios de dichos servicios se han generado múltiples problemas. El primero es la intervención de las comunicaciones por particulares. Esta situación se encuadra en la perspectiva penal del título quinto, denominado Delitos en Materia de Vías de Comunicación y Correspondencia que, en el capítulo segundo de la violación de correspondencia, prescribe en su artículo 177: «A quien intervenga comunicaciones privadas sin mandato de autoridad judicial competente se le aplicarán sanciones de seis a doce años de prisión y de trescientos a seiscientos días multa» ${ }^{16}$.

Un segundo problema es el de la práctica de intervención de las comunicaciones que llevan a cabo de manera sistemática las autoridades, al que se le ha calificado como «ilícito espionaje» que, a decir de Sergio García Ramírez, ha motivado «intensas polémicas y en no pocas ocasiones ha sido materia de escándalo» ${ }^{17}$.

Sobre la base de lo anterior, podemos distinguir la existencia de dos figuras jurídicas distintas: la primera de ellas es la intervención de las comunicaciones y, la segunda, la vigilancia vinculada a la investigación de delitos por parte de la autoridad competente. 


\section{III.1. 4. Arraigo como medida cautelar}

La palabra «cautela» proviene de latín cautela y significa «precaución y reserva con que se procede». Sin embargo, no debe pasar desapercibido que, tal y como la define la Real Academia de la Lengua Española en su segunda acepción, también es indicativa de «astucia, maña y sutileza para engañar.»

Por otra parte, cautelar significa «preventivo o precautorio», y en su segunda acepción, «dícese de las medidas o reglas para prevenir la concesión de determinado fin o precaver lo que pueda dificultarlo». Por otro lado, en lo que respecta a la palabra «precautorio», es indicativa de lo que «precave o sirve de precaución». «Precaución, reserva o cautela para evitar o prevenir los inconvenientes, dificultades o daños que puedan temerse».

En este sentido, Conde-Pumpido Tourón señala que «por tales medidas cabe entender las resoluciones motivadas del órgano jurisdiccional, que pueden adoptarse contra el presunto responsable de la acción delictuosa, como consecuencia, de un lado, del surgimiento de su cualidad de imputado y, de otro, de la fundada probabilidad de su ocultación personal o patrimonial en el curso de un procedimiento penal, por las que se limita provisionalmente la libertad o la libre disposición de sus bienes con el fin de garantizar los efectos, penales y civiles, de la sentencia» ${ }^{18}$.

Esta definición nos permite arribar a un sentido más amplio, entendido como «una medida precautoria dictada por el juzgador, a petición de parte, cuando hubiere temor de que se ausente u oculte la persona contra quien deba entablarse o se haya entablado una demanda. Tiene por objeto o finalidad impedir que el arraigado abandone el lugar del juicio sin dejar un apoderado que pueda contestar la demanda, seguir el proceso y responder de la sentencia que se dicte» ${ }^{19}$.

Asimismo, puede definirse como el acto formal y materialmente jurisdiccional que durante un período de tiempo determinado prohíbe a una persona, a la que se le está integrando una averiguación previa o sustanciándose un proceso por el término constitucional que deba resolverse, que abandone un lugar específico, siempre y cuando exista el riesgo fundado de que se sustraiga a la acción de la justicia.

Pese al nombre de arraigo domiciliario, este no se practica en el domicilio de la persona, sino que se extiende a casas de seguridad u hoteles designados discrecionalmente. Además, no se ha precisado en ninguna forma si el arraigado puede sustraerse del lugar designado, si puede permanecer o recibir la compañía de su familia o si puede seguir trabajando.

18 CONDE-Pumpido TOURÓn, Cándido et al. Los procesos penales. Comentarios a la Ley de Enjuiciamiento Criminal, con formularios y jurisprudencia. Tomo 4. Barcelona: Bosch, 2000, p. 16 y siguientes.

19 Instituto de Investigaciones Jurídicas de la UNAM. Diccionario Jurídico Mexicano. México D. F.: Editorial Porrúa-UNAM, 1997. 
En fin, no existe regulación alguna sobre el ejercicio de los derechos que le corresponden, omisión que, sin duda alguna, propicia el exceso y abuso por parte de quien lo ordena y de quien lo ejecuta.

De lo anterior se puede inferir que estamos hablando de un arraigo susceptible de aplicarse indistintamente en materia civil o penal ${ }^{20}$, sin dejar de creer que pueda ser una figura jurídica aplicable en cualquier otro tipo de proceso. Igual, tal texto definitorio es de gran ayuda para hablar, más adelante, del arraigo en materia penal.

Para tal efecto es pertinente invocar la definición del Diccionario Jurídico Mexicano, del Instituto de Investigaciones Jurídicas de la UNAM: «[...] la medida precautoria que tiene por objeto asegurar la disponibilidad del inculpado en la investigación previa o durante el proceso, cuando se trate de delitos imprudenciales o de aquellos en los que no proceda la prisión preventiva».

Por su parte, Díaz de León ${ }^{21}$ señala que, «en nuestro sistema procesal penal, el arraigo es una medida cautelar que durante la averiguación previa se impone con vigilancia de la autoridad al indiciado, para los efectos de que este cumpla con los requerimientos del Ministerio Público, en razón de la investigación de un hecho delictivo (figura establecida en el artículo 133 bis del Código Federal de Procedimientos Penales). Es decir, las medidas en los procedimientos penales pueden ser también de carácter personal para garantizar el desarrollo del proceso, así como la efectividad de la sanción privativa de libertad, en los casos de sentencias condenatorias de tal pena».

\section{III.1.5. Detención}

La detención se encuentra, en un primer orden, como medida cautelar de carácter personal. Fenech la define como «un acto por el que se produce una privación de la libertad individual de carácter provisional y que tiene por fin (a la persona inculpada) ponerla a disposición mediata

20 Por su parte, AGUILAR LÓPEZ, Miguel Ángel. «El arraigo domiciliario». Revista Tepantlato, № 23 , México, 2003, pp. 15 y siguientes. El autor distingue entre arraigo civil, laboral y penal: «En la legislación vigente debe distinguirse el arraigo civil, previsto legalmente como una medida precautoria dictada por el juzgador, a petición de parte, cuando hubiere temor de que se ausente u oculte la persona contra quien deba entablarse o se haya entablado una demanda, con el objeto de impedir que abandone el lugar del juicio sin dejar un apoderado que pueda contestar la demanda, seguir el proceso y responder de la sentencia que se dicte, medida que incluso puede solicitarse contra los tutores, albaceas, socios y administradores de bienes ajenos. En materia laboral, el arraigo no procede cuando la persona contra quien se pide sea propietaria de una empresa establecida; quien quebrante el arraigo en los términos del artículo 242 del Código de Procedimientos Civiles, será castigado con la pena que señala el Código Penal al delito de desobediencia a un mandato legítimo de la autoridad pública, quedando sujeto a las medidas de apremio que el juez dicte para obligarlo a regresar al lugar del juicio. En atención a su origen y naturaleza jurídica, en Materia Penal, el arraigo es la medida precautoria que tiene por objeto asegurar la disponibilidad del inculpado durante la indagatoria o el proceso penal, cuando se trate de delitos culposos o de aquéllos en los que no proceda la prisión preventiva».

21 Diccionario de Derecho procesal penal y de términos usuales en el proceso penal. Cuarta edición. México: Editorial Porrúa, 1997, p. 172. 
o inmediata, del instructor del proceso penal para los fines de éste, en la expectativa de su posible prisión provisional $\gg^{22}$.

Otra definición que nos ha proporcionado la doctrina en relación con la detención es la que maneja López Barja al señalar que, «es una medida cautelar por la que se priva de la libertad a una persona con la finalidad de ponerla a disposición judicial. Por esencia, su duración es necesariamente corta ${ }^{23}$.

Por otra parte, Vicente Gimeno señala que la detención es «una medida cautelar de naturaleza personal y provisionalísima que puede adoptar la autoridad judicial, policía e incluso los particulares, y consiste en la limitación del derecho a la libertad personal del imputado con el objeto esencial, bien poner a disposición de la autoridad judicial, bien si se encuentra ya en dicha situación, de resolver sobre la misma, restableciendo dicho derecho de adoptar una medida cautelar menos interina» ${ }^{24}$.

De lo anterior podemos concluir que la detención es una medida de aseguramiento de carácter personal, que tiene como objetivo limitar el derecho a la libertad personal de un individuo, en virtud de que se le imputa un delito. La temporalidad de la medida es limitada por los plazos establecidos constitucionalmente.

\section{III.1.6. Órdenes de aprehensión}

De acuerdo con el artículo 16, párrafo segundo, no podrá librarse una orden de aprehensión sino por la autoridad judicial, y sin que preceda denuncia o querella de un hecho que la ley señale como delito, sancionado cuando menos con pena privativa de libertad, y que existan datos que acrediten el cuerpo del delito y que hagan probable la responsabilidad del indiciado.

El principio de legalidad y la garantía de audiencia previa como derechos del hombre obligan a la existencia de un juicio para que en la sentencia se pueda afectar la esfera jurídica de los particulares. Esta regla general tiene excepciones que se manifiestan en el Derecho penal.

La orden de aprehensión es un acto de autoridad, en virtud del cual el juez competente determina la detención de un gobernado, al inicio del proceso penal o durante este, sin que exista la sentencia que declare que se ha cometido el delito y que el inculpado es responsable penalmente.

Para dictarla, debe probarse en la averiguación previa que la conducta está tipificada como delito en la ley, y merece pena corporal, y que

MEDIDAS DE

ASEGURAMIENTO

Y REFORMA

PENAL: UNA

PERSPECTIVA

DESDE LOS

DERECHOS

HUMANOS 
existen pruebas que demuestren la probable responsabilidad penal del inculpado.

En virtud de la orden de aprehensión se priva de libertad al ciudadano contra quien se gire, pero es una prisión provisional que puede suspenderse en virtud de la libertad caucional, y cuya duración se inicia en el momento de la detención y hasta que se resuelva la situación jurídica del indiciado. Si la privación de la libertad perdura después de decretada la formal prisión, el acto de autoridad que le da origen ya no será la orden de aprehensión, pues la prisión preventiva dimana de la formal prisión dictada ${ }^{25}$.

Dentro del artículo 16 de la Constitución existen algunos requisitos que hay que cumplir para que se pueda dictar la orden de aprehensión. Estos son que exista denuncia, querella o acusación.

Del contenido de los artículos 21 y 102 del Constitución Política, se desprende la función investigadora del Ministerio Público en su calidad de representante social y titular de la acción penal, ya que «el único facultado para solicitar la orden de aprehensión es el Ministerio Público atribución que deberá asumir después de que haya ejercitado la acción penal y consignado los resultados investigatorios de la averiguación previa. Sólo de esa forma el juez estará material y jurídicamente facultado para dictar su acto de autoridad». ${ }^{26}$

El único órgano con atribuciones constitucionales para dictar las órdenes de aprehensión es la autoridad judicial, pero no basta que sea judicial; además, debe ser autoridad competente, según lo prescribe el texto constitucional del artículo 16.

Todo acto de molestia, en particular la aprehensión del gobernado, para ser válido deberán de cumplir con determinadas formalidades: (a) estar consagrada por escrito y firmada por el titular del órgano que la dicta; (b) ser formulada por autoridad competente; y (c) estar fundada y motivada. «Para acreditar la existencia del delito y la supuesta responsabilidad penal del inculpado, basta que las prueba testimoniales sean recibidas en la averiguación previa; además, serán suficientes las declaraciones de familiares del sujeto pasivo del delito para acreditar los extremos legales dictados por el art. 16 de la Constitución».27

Es preciso señalar que las autoridades administrativas no cuentan con facultades para detener a ningún individuo cuando este ha cometido alguna falta contra los Reglamentos de Policía y Buen Gobierno. Deben limitarse a levantar el acta correspondiente y a permitir que la autoridad competente le imponga la sanción correspondiente a la infracción.

25 MANCILLA OVANDO, Jorge. Las garantías individuales y su aplicación en el proceso penal. Quinta edición. México: Porrúa, 1993, pp. 111. 
En casos urgentes, «si no hay ninguna autoridad judicial en el lugar del hecho, y se trata de delitos perseguibles de oficio, la autoridad administrativa tiene la facultad extraordinaria de decretar la detención de un acusado, y ponerlo inmediatamente a disposición de la autoridad judicial». ${ }^{28}$

\section{III.2. Respecto de bienes muebles o inmuebles}

En lo que se refiere a las medidas de carácter real, es importante señalar que no se circunscriben al ámbito del Derecho civil. Alcalá Zamora señala que dichas medidas tienen el propósito de garantizar el disfrute de un beneficio procesal de la libertad y de asegurar la reparación del daño causado por la comisión de algún ilícito sancionado conforme a la norma penal.

Para López Barja, por otro lado, dentro de las medidas cautelares reales podemos englobar «todas aquellas que tengan como objeto bienes muebles o inmuebles y cuya finalidad sea preservar los bienes en base a los intereses propios del proceso penal en el que recaen ${ }^{29}$.

Para Silva Silva, «las medidas cautelares reales (garantías reales) afectan de alguna manera el eventual resultado que se dé en las medidas definitivas (afectación de bienes) ${ }^{30}$.

Podemos observar las medidas cautelares reales desde cuatro ángulos diversos: «a) Medidas que aseguran la ejecución de una pretensión de condena al pago del resarcimiento del daño causado con motivo del delito, trátase de medidas esencialmente de carácter civil; b) Medidas que aseguran la ejecución de una pretensión de condena a la perdida de alguna cosa; c) Medidas que aseguran o conservan alguna cosa, hasta en tanto se decide en definitiva quién tiene mayor derecho sobre la misma; c) Medidas que aseguran fuentes de prueba ${ }^{31}$.

\section{III.2.1. A la propiedad o posesiones}

Es importante señalar que la CPEUM, por medio del artículo 14, segundo párrafo, protege a los gobernados en contra de cualquier acto de privación, ya sea de un derecho real de propiedad sobre un bien mueble o inmueble y, en general, la posesión, sea esta de buena fe o de mala fe.

Es preciso señalar que las figuras de hipoteca, fianza y embargo no son propiamente actos de privación, ya que los bienes todavía se encuentran dentro de la esfera jurídica del gobernado. Tal es el caso de los embargos, debido a que el sujeto podrá recuperar el objeto hasta un momento antes de que se dé la adjudicación en un remate, siempre y cuando cubra la obligación.

MEDIDAS DE

ASEGURAMIENTO

Y REFORMA

PENAL: UNA

PERSPECTIVA

DESDE LOS

DERECHOS

HUMANOS 


\section{III.2.2. A la inviolabilidad del domicilio}

La inviolabilidad del domicilio es una garantía consagrada en el artículo 16, párrafo primero, de la CPEUM. Dicha inviolabilidad alude a la imposibilidad formal que tiene la autoridad para llevar a cabo el registro del hogar en el que habita una persona; garantía que tiene por objeto la protección de la privacidad, la que, a su vez, únicamente podrá ser invadida por medio de mandamiento escrito de autoridad competente, que funde y motive la causa legal del procedimiento.

Desde una perspectiva constitucionalista, podemos afirmar que el término domicilio no solo se circunscribe al lugar en el que una persona tiene su habitación, ya sea de manera permanente o transitoria, sino que también alude al lugar de trabajo, ya que la inviolabilidad del domicilio es un secuela indispensable de la libertad personal.

Es importante señalar que la inviolabilidad del domicilio cuenta con dos excepciones: las órdenes de cateo y las visitas domiciliarias.

De lo anterior, podemos afirmar que la «inviolabilidad del domicilio no es absoluta, no puede detener el curso de la justicia, proteger a los delincuentes o imposibilitar la obtención de la prueba de su culpabilidad como lo es el caso de los cateos» ${ }^{32}$.

La inviolabilidad del domicilio es un principio relativo, $\mathrm{y}$ «debe ceder en los casos y en las formas previstas de forma excepcional por la ley», como lo señala el artículo 16 constitucional para los cateos. «El Código Penal fortalece la garantía, pues tipifica como delito cometido por los servidores públicos el ordenar o practicar cateos fuera de los casos autorizados por la ley $(225, \mathrm{XVIII}) »$.

Para que una orden de cateo sea legal, deberá satisfacer los siguientes requisitos:

1) debe emanar de autoridad judicial competente, es decir, únicamente puede dictarla un juez penal, local o federal; 2) Debe constar en mandamiento escrito, fundado y motivado y 3) Debe precisar el lugar que ha de inspeccionarse, la persona o personas que hayan de aprehenderse y los objetos que se buscan, a lo que únicamente debe imitarse la diligencia, quiere esto decir que no pueden ordenarse cateos generales, con finalidad indefinida ${ }^{33}$.

A decir de Zamora-Pierce, la Suprema Corte de Justicia de la Nación, en constante y reiterada jurisprudencia, ha destruido cabalmente la garantía de inviolabilidad del domicilio:

Si el amparo, que es el único procedimiento establecido por nuestras leyes para proteger a los individuos de los actos de la autoridad que violen las garantías individuales, no es apto, en opinión de la SC, para 
reparar las violaciones resultantes de cateos y detenciones que se practican sin orden judicial, entonces esas garantías carecen de protección. Si la policía, sin preocuparse por obtener previamente órdenes judiciales, irrumpe en un domicilio y priva de su libertad a una persona y se apodera de diversos documentos, y si, posteriormente el MP ejerce acción penal consignando la averiguación previa con detenido y acompañando, como pruebas, los documentos de los que se hizo ilegalmente, y si, finalmente, los tribunales no liberan al detenido y le otorgan valor probatorio a los documentos, debemos preguntarnos qué trascendencia tiene el consagrar la garantía de inviolabilidad del domicilio en la Constitución, dado que las cosas ocurren exactamente como lo harían en dicha garantía no hubiese sido jamás establecida en nuestra Carta Magna ${ }^{34}$.

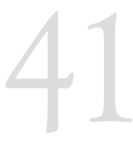

MEDIDAS DE ASEGURAMIENTO Y REFORMA

PENAL: UNA PERSPECTIVA DESDE LOS DERECHOS HUMANOS

\section{III.2.3. La intromisión domiciliaria en caso de delito grave y en flagrancia} En relación con estos temas es necesario remitirnos a dos resoluciones de la SCJN recientemente emitidas. En la primera se explica que, de acuerdo con la garantía de inviolabilidad del domicilio, la orden emitida por la autoridad judicial debe reunir los requisitos previstos en el artículo 16 de la Constitución. De lo contrario dicha orden, y las pruebas que se hayan obtenido como consecuencia directa de la misma, carece de existencia legal y eficacia probatoria. Por otra parte, se emitió una segunda resolución en el sentido de que la intromisión de la autoridad en un domicilio, sin orden judicial, contará con eficacia de las actuaciones realizadas y de las pruebas obtenidas cuando es motivada por la comisión de un delito en flagrancia.

Dicha tesis, emitida por la Suprema Corte, tiende a convalidar las injerencias arbitrarias en el domicilio por parte de los órganos del poder público, ya que al reconocerles eficacia probatoria se ven incentivados a aducir dicha causa para justificar su actuación.

\section{DERECHO A LA LIBERTAD Y ASEGURAMIENTO DE} PERSONAS, ASÍ COMO LA INTROMISIÓN DOMICILIARIA Hoy en día, se observa con gran preocupación la aplicación del arraigo como una medida precautoria ejecutada por los agentes del Ministerio Público, cuya práctica y efectos no regulados colocan en grave riesgo e, incluso, lesionan diversos derechos humanos de los arraigados. Por tales motivos es que resulta necesario examinar la manera en la que se aplica esta figura procesal, en pro de las investigaciones por parte de las autoridades competentes. Sin embargo, falta un marco legal acorde con la aplicación de esta medida precautoria, la que conlleva a la violación de los derechos humanos relativos a la presunción de inocencia, libertad personal, libertad de tránsito, libertad de trabajo y derecho al buen nombre, entre otros. 


\section{IV.1. La interpretación de la Suprema Corte de Justicia de la Nación sobre el arraigo}

El pleno de la Suprema Corte de Justicia de la Nación declaró, por mayoría de votos, la inconstitucionalidad de la figura del arraigo domiciliario para retener a presuntos delincuentes mientras se realizan investigaciones y se reúnen elementos de prueba en su contra.

Por ocho votos contra uno, y al desahogar la controversia 20/2003 presentada por la minoría legislativa el Congreso del estado de Chihuahua, los ministros determinaron la invalidez del artículo 122, bis, del Código de Procedimientos Penales de aquella entidad, que contempla el arraigo de sospechosos por treinta días.

Dicha resolución —que causó jurisprudencia, pues alcanzó los ocho votos necesarios para ello- se basó en la consideración de que la Constitución no permite privaciones de la libertad por parte del Ministerio Público por más de 48 horas, 96 horas en casos de delincuencia organizada.

«Ningún precepto de la Constitución establece el arraigo penal, figura jurídica que afecta la libertad personal; de ese modo, por mayoría de 8 votos se determinó que este precepto es inconstitucional», aseguró al término de la sesión el ministro ponente Juan Díaz Romero.

También aclaró que dicha figura deberá ser derogada únicamente del Código de Procedimientos Penales de Chihuahua, pues la resolución no es genérica a la legislación del país, y reconoció que aquellas personas que pretendan ser sometidas a arraigo en cualquier parte de la república pueden evitarlo por la vía del amparo.

Existe ya en la Primera Sala una contradicción de tesis, donde los señores ministros determinaron que sí afecta la libertad personal, no solamente la libertad de tránsito; el proyecto que se ha discutido es parte de ese criterio establecido. La resolución de los ministros no tiene aspectos relacionados con la conveniencia o no del arraigo, sino con la afectación a la libertad personal que causa esta figura, de acuerdo con algunos artículos de la Constitución.

«El constituyente fue muy específico en los tiempos de privación de la libertad personal del indiciado», explicó el ministro Juan Díaz Romero, autor de la sentencia, «no veo la conveniencia o no de que exista el arraigo, sólo digo que no coincide con las reglas de la Constitución». También aseguró que aun cuando el arraigo es conveniente, para establecerlo como constitucional es necesario reformar la Constitución, para establecer — después de la detención, la orden de aprehensión, la detención en flagrancia-, el arraigo penal. «Pero mientras no esté, cuando menos, en lo que se refiere al Código de Procedimientos Penales del estado de Chihuahua, es inconstitucional», finalizó en la sesión. 


\section{2. Derechos humanos y Derecho procesal penal}

Las constantes trasformaciones sociales y el incremento en los índices delictivos ha hecho evidente «[...] el temor que vive la ciudadanía por el incremento en la comisión de delitos y por los altos riesgos que provoca el hampa que transita por la calle y por las carreteras, libremente y sin castigo, vulnerando bienes jurídicamente tutelados» ${ }^{35}$. Dicha situación impone al Estado la obligación de garantizar adecuadamente la procuración e impartición de justicia en nuestro país.

A decir de Velásquez V. Fernando:

[...] en un país como México, con sus ya cotidianas violaciones de los derechos humanos y sus manifiestos desequilibrios sociales, es obligación de los estudiosos del Derecho penal continuar con la difusión de estos postulados y luchar porque el sistema penal venidero los torne realidad, pues no basta con las consagraciones legislativas para lograr un sistema más o menos coherente de principios, sino que se requiere el trabajo académico, jurisprudencial e incluso la lucha política ${ }^{36}$.

\section{IV.3. La potestad punitiva del Estado: consideraciones especiales sobre la aplicación del arraigo}

Antes de entrar al análisis de los derechos humanos que se violan —al extralimitarse el objetivo y término del arraigo—es oportuno señalar que, en nuestro país, el Estado de Derecho sienta sus bases en la Constitución Política de los Estados Unidos Mexicanos, en cuyo texto se reconoce un capítulo de derechos fundamentales que buscan garantizar el bien común, la justicia y la seguridad jurídica de los gobernados mediante el principio de legalidad ${ }^{37}$. Más aun, tanto la Carta Magna como los tratados internacionales en materia de derechos humanos ratificados por nuestro país, establecen el régimen de garantías que deberá respetar la autoridad cuando emita un acto hacia los gobernados ${ }^{38}$, y, por otro lado,

35 «La justicia social y penal». En Sergio García Ramírez (coordinador). Derecho penal. Memoria del congreso internacional de culturas y sistemas jurídicos comparados. II. Proceso penal. México: Instituto de Investigaciones Jurídicas/UNAM, 2005, pp. 88.

36 «Los 'principios y garantías penales' en el Código penal para el Distrito Federal mexicano de 2002". En Moisés Moreno Hernández y Rodolfo Félix Cárdenas (coordinadores). Comentarios en torno al Nuevo Código Penal para el Distrito Federal. México: CEPOLCRIM, 2003, p. 64 y siguientes.

$37 \mathrm{Al}$ respecto, Malo Camacho, Gustavo. Derecho penal mexicano. México: Porrúa, 1997, p. 152. «Existe una estrecha relación entre el derecho penal y los derechos humanos». Con ello enuncia los ordenamientos jurídicos existentes (nacionales e internacionales) en los cuales se implican una serie de principios fundamentales: «entre otros aspectos, se refieren a la prohibición de la tortura y de las penas y tratos crueles, inhumanos o degradantes [...] En general, establecen bases fundamentales vinculadas con un procedimiento que respete el alcance de los principios de legalidad, jurisdiccionalidad y de la dignidad e incolumidad de las personas. Todas estas disposiciones, naturalmente complementan y reafirman, en su caso, el contenido de las disposiciones previstas en la constitución política de cada uno de los Estados y sirven para conformar y delimitar las características del ius puniendo, a nivel internacional e interno, conformando con ello las bases de una conciencia universal acerca del respeto a la persona». Igualmente, véanse las aportaciones de DíEZ RIPOLLÉs, José Luis. La racionalidad de las leyes penales. Madrid: Trotta, 2000.

38 Más en detalle, véase el estudio de FERNÁNDEZ SANTILLÁN, José F. Locke y Kant. Ensayo de filosofía política. México: Fondo de Cultura Económica, 1996; FERRY, Luc/Alain RENAUT. Filosofía política, III. De los derechos del hombre a la idea republicana. México: Fondo de Cultura Económica, 1997; FERRAJOLI, Luigi. Derecho y razón. Teoría del garantismo penal. Madrid: Trotta, 2004, esencialmente

MEDIDAS DE

ASEGURAMIENTO

Y REFORMA

PENAL: UNA

PERSPECTIVA

DESDE LOS

DERECHOS

HUMANOS 
el Estado cuenta con la facultad de ejercer la potestad punitiva ${ }^{39}$ cuando sea necesario investigar un delito y fijar las penas que correspondan.

Del mismo modo, no debemos soslayar que el arraigo es cuestionado con el argumento de que carece de fundamento en la Constitución Política de los Estados Unidos Mexicanos; pero que, sin embargo, es utilizado como medida precautoria para asegurar la disponibilidad del inculpado en la integración de una averiguación previa y, en su caso, durante el proceso y la ejecución penal.

A partir de la última década se ha presentado con mayor frecuencia el uso de una figura jurídica que permaneció con una aplicación muy restringida y que, en abril de 2001 en el seno de la Conferencia de Procuradores, se propuso ampliar: la figura del arraigo o arresto domiciliario no hotelero o en casa de seguridad, sino en el domicilio; para así garantizar — señalaron los procuradores - una mejor procuración de justicia y, en tal virtud, facultar al Ministerio Público para decretarlo de manera directa sin la intervención de la autoridad judicial.

Es indudable que las reformas de los últimos años se han sustentado, precisamente, en esa oferta o propuesta política; la de suponer que limitar los derechos de los particulares, eliminar algunas garantías individuales y anular lo que llaman trabas jurídicas pueda dar como resultado una mejor procuración de la justicia y, en consecuencia, incrementar los niveles de seguridad pública. Sin embargo, no hemos avanzado mucho y las reformas continúan, y se siguen presentando propuestas sobre esta materia sin que se llegue a un consenso que permita vislumbrar una mejor procuración de justicia en nuestro país ${ }^{40}$.

\section{IV.4. Estado actual del arraigo en la práctica}

En el contexto antes planteado, el arraigo es una medida precautoria, una medida cautelar que se importó de la materia civil. Se la sustrajo del Código de Procedimientos Civiles que, desde sus orígenes, aludía propiamente a las medidas precautorias, a las cautelares que tuvieran a bien garantizar que la materia de la litis continuara subsistente, y no se previó, en forma alguna, como pena, como consecuencia jurídico penal.

pp. 33-44; MORENO HERNÁNDEZ, Moisés. «Principios rectores en el derecho penal mexicano». Criminalia, año LXIV, N³, septiembre-diciembre, México, 1998, especialmente, pp. 152-160.

39 VELÁSQUEZ, Fernando. «Los 'principios y garantías penales' en el Código penal...». Ob. cit. pp. 67-70. El autor desarrolla los postulados que fundamentan el poder del Estado en el ejercicio de la potestad punitiva.

40 Sobre el particular, ha propuesto MANCERA ESPINOSA, Miguel Ángel. «La necesidad de un cambio en la reforma...». Ob. cit., p. 190. Dice el autor: «[...] es necesario analizar la posibilidad de incluir en nuestro proceso penal principios como el de 'oportunidad', y figuras procesales como las de la 'solución anticipada' y la 'mediación', a fin de evitar los gastos económicos y temporales que son en muchos de los casos innecesarios ante la levedad de la vulneración del ordenamiento jurídico y que por lo mismo, para cuando el resarcimiento del daño, éste pierde todo sentido para las víctimas del delito, por lo que en estas situaciones, el aceptar una terminación anticipada del proceso penal, bajo la condicionante de la reparación del daño, entre otras, resulta conveniente». 
Sin embargo, en términos actuales se puede percibir algo muy claro: el arraigo ha dejado de ser una medida precautoria y se ha vuelto, en su práctica, una consecuencia jurídico penal, una pena trascendental que no ha sido decretada o impuesta por un juez. Para explicar lo anterior y no extendernos en el tema basta mencionar un ejemplo: una persona que ha sido arraigada durante treinta, sesenta o noventa días, aunque dependerá del lugar de la República en el cual nos encontremos y el ámbito local o federal que tomemos como referencia, no le es computado el tiempo de arraigo para efectos de la pena. En ese orden de ideas vale preguntarnos, ien qué calidad se encuentra el individuo, como preso? ¿Qué tipo de detención es esta? ¿Qué derechos le corresponden?

La persona que es investigada y detenida ha sido materialmente privada de su libertad; estamos de acuerdo con la privación de su libertad personal, pero una de las consecuencias jurídico penales de mayor gravedad que se le pueden infligir a una persona en un Estado democrático y de derecho es, precisamente, la privación de ese derecho. En nuestro país, tenemos proscrita la pena de muerte y, entonces, el siguiente bien jurídico que se le puede limitar de manera más grave a una persona es el de la libertad personal.

Hoy por hoy, encontramos que el arraigo limita el derecho a la libertad personal sin que se tome en consideración para efectos de la pena. Lo más grave es que sucede cuando resulta que no hay responsabilidad penal. Sucede, pues, que para privar del derecho a la libertad no hay un marco jurídico claro; entonces, los efectos de la medida precautoria del arraigo se han dirigido hacia un horizonte completamente distinto del que le corresponde.

El uso del arraigo hasta hace algunos años era poco común. Pero, también, a partir de entonces, nos hemos percatado de que cada día lo utilizan con una mayor frecuencia. Cuando lo comparamos con la detención ante el agente del Ministerio Público, con la reclusión preventiva y con la prisión, encontramos serias diferencias y una gran sorpresa.

Sobre la base de lo anterior, se puede concluir que la medida cautelar, o precautoria, genera consecuencias más graves, y limita derechos con una mayor gravedad y severidad, que las de la detención ante el agente del Ministerio Público, la prisión preventiva y, en su caso, la prisión por una medida cautelar. Pero, ia qué nos referimos?

Cuando una persona se encuentra arraigada, lo más común es que el arraigo no se lleve a cabo en su domicilio, sino en lo que se denominan casas de seguridad; estas son designadas discrecionalmente por quien está llevando a cabo la práctica de la medida, o bien en hoteles, donde habrá que ver si el hotel garantiza la seguridad de la persona y si el arraigo domiciliario previsto puede llevarse a cabo en uno. Si fuera así, tendríamos que preverlo, más bien, como arraigo hotelero y consideremos de qué clase de hotel se trata. Entonces, una persona en un reclusorio

MEDIDAS DE ASEGURAMIENTO Y REFORMA PENAL: UNA PERSPECTIVA DESDE LOS DERECHOS HUMANOS 
preventivo, o ante el agente del Ministerio Público, tiene derecho a no estar incomunicado, a recibir visitas, a un trato digno y, lo más importante, a todo un marco jurídico muy desarrollado sobre la materia que prevé con toda claridad qué gama de derechos pueden ser gozados por la persona en su caso específico.

El régimen jurídico del arraigo, en su situación actual, no establece en forma alguna los derechos que tendrá la persona sujeta a dicha medida: si podrá ser sustraído de la casa de seguridad o del hotel a la hora que determine el agente del Ministerio Público, si podrá estar en el arraigo en compañía de su familia o sin esta, si podrá seguir con la realización de sus actividades o alguna de ellas, o bien, si podrá seguir trabajando y gozar de su derecho al buen nombre y a la imagen, en ejercicio de los derechos y las prerrogativas que le corresponden como persona.

$\mathrm{Al}$ respecto, cabe señalar los efectos comparativos del arraigo: detención ante el Ministerio Público, reclusión preventiva, prisión preventiva y prisión como ejecución de pena. Al confrontarlos con las figuras anteriores, resulta claro que el régimen jurídico a que se encuentra sujeto el arraigo en la actualidad se presenta difuso, por no decir que se encuentra al margen de cualquier regulación, lo que propicia el exceso y abuso por parte de quien lo ejecuta.

\section{5. Los efectos del arraigo}

En primer lugar, corresponde señalar que el arraigo atenta flagrantemente contra la presunción de inocencia en los términos que se aplican hoy en día. Además, si la detención preventiva y el tema de la libertad provisional bajo caución atentan ya contra la presunción de inocencia ni qué decir del tema del arraigo domiciliario. Esta es una medida cautelar que se lleva a la práctica de manera extralegal y, como ya se ha mencionado, usualmente fuera del domicilio — en hoteles o casas de seguridad—, en la que, además, no queda en claro qué tipo de derechos tendrá la persona; motivo por el cual, indudablemente, se atenta contra su derecho a la libertad personal. De esto se desprende que el individuo sometido a esta medida está, prácticamente, sirviendo una pena sin que exista sentencia en su contra.

En segundo lugar, se afecta su derecho a la libertad personal y de tránsito, toda vez que no puede trasladarse de una parte a otra en su propia ciudad, en su propio país ni salir de este,. Pero, sobre todo, no puede gozar de su libertad de manera plena.

En tercer lugar, atenta en todo caso contra su derecho al trabajo, pues una persona que se encuentra arraigada está negada de este derecho. Si después se determina que no hay responsabilidad alguna que imputar en su contra, iqué sucede con su trabajo, su imagen, su buen nombre y el de su familia? ¿Dónde queda el derecho de permanecer en compañía de esta? 
Realmente se han dejado en un lindero estos temas, y es necesario volver orientar la mirada hacia ellos. Se debería poder plantear una propuesta que permita superar la grave situación en la que se encuentra el arraigado y, en última instancia, analizar el carácter trascendente e inusitado del arraigo.

Actualmente es posible aplicar el arraigo a los probables responsables de la comisión de un delito, pero también a los testigos y las víctimas u ofendidos por el delito. ¿Es válido, acaso, arraigar a los testigos, la víctima y/o el ofendido? Parece ser delicado en extremo y, evidentemente, es un exceso en el que cae esta propuesta de reforma legal. En consecuencia y desde nuestro punto de vista, esta situación es totalmente rechazada y reprobable.

Por ello, consideramos que es conveniente trabajar sobre la base de cuatro propuestas para reorientar esta práctica - tan deficiente a nuestro parecer-y con ello ajustarla a un marco jurídico acorde con la realidad mexicana.

\section{6. El arraigo y los derechos humanos}

En el momento de su creación, en el Código Penal mexicano no existía propiamente la figura del arraigo —entendida en cualquiera de las acepciones antes aludidas- y no apareció hasta la reforma de $1983^{41}$. Para entonces, lo que se pretendía originalmente era tratar de producir una mínima molestia a aquella persona respecto de la cual existieran indicios, más no sospecha, de que había participado en la comisión de

41 García RamíREZ, Sergio. "Consecuencias del delito: los sustitutivos de la prisión y la reparación del daño». Boletín Mexicano de Derecho Comparado, № 107, México. «En 1983, la introducción de los sustitutivos se hizo dentro de fronteras racionales, que permitieran una operación eficiente. A este respecto, conviene referirse a lo que podríamos denominar condiciones cualitativas y cuantitativas -que se articulan en la 'lógica del sistema'-, en las que sucesivas modificaciones legales han traído zigzagueos e inconsecuencias que no contribuyeron a la debida comprensión y al buen arraigo del sistema. Esas variaciones fueron resultado, a su vez, de los cambios en la incidencia criminal o en la percepción acerca de las reacciones adecuadas frente al crecimiento de la criminalidad. En su conjunto, estos movimientos ponen de manifiesto lo que se ha denunciado de manera tan frecuente como infructuosa: la ausencia de una política criminal que fije el cauce para la reforma penal y mida la pertinencia de las nuevas figuras e instituciones. Hoy día pudiera resultar difícil —pero no por ello impracticable-, ante una opinión pública sensible e irritada, la incorporación muy amplia de los sustitutivos y de las alternativas tanto en la legislación como en la aplicación judicial. No la favorece el auge de la criminalidad, una realidad cotidiana, incontenible -o incontenida- y notoria».

Para mayor abundancia de la reforma de 1983, véanse esencialmente, ISLAS DE GoNZÁLEZ MARISCAL, Olga. "Comentarios a las reformas al Código Penal». En La reforma jurídica de 1983 en la administración de justicia. México: Procuraduría General de la República, 1984, pp. 335-337; MADRAZO, Carlos A. La reforma penal (1983-1985). México: Porrúa, 1989, pp. 245 y siguientes; MALO CAMACHO, Gustavo. "La reforma de 1984 al Código Penal. Parte general. Algunos comentarios». En La reforma jurídica de 1983 en la administración de justicia. México: Procuraduría General de la República, 1984, p. 295; MORENO HERNÁNDEZ, Moisés. «Algunas consideraciones sobre las reformas a la Parte Especial del Código Penal». En La reforma jurídica de 1983 en la administración de justicia, México: Procuraduría General de la República, 1984, p. 381; PAVÓn VASCONCELOS, Francisco. Las reformas penales (análisis crítico de la parte general). México: Porrúa, 1985; PORTE PETIT CANDAUDAP, Celestino. «Reformas penales de 1984. Parte general (el delito)». En La reforma jurídica de 1983 en la administración de justicia. México: Procuraduría General de la República, 1984, pp. 229-230; VeLA TREVIÑo, Sergio. «Algunas consideraciones sobre la reforma penal de 1984». En La reforma jurídica de 1983 en la administración de justicia. México: Procuraduría General de la República, 1984, p. 367; pp. 83-87 y 117-118. 
un delito, tal y como lo ha sostenido la tesis 1a./J. 78/99, emitida por la Primera Sala de la Suprema Corte de Justicia de la Nación, con la siguiente rúbrica ${ }^{42}$ :

\begin{abstract}
ARRAIGO DOMICILIARIO, ORDEN DE. AFECTA LA LIBERTAD PERSONAL. La orden de arraigo domiciliario prevista por el artículo 133 bis del Código Federal de Procedimientos Penales, antes y después de su reforma mediante decreto publicado en el Diario Oficial de la Federación de fecha ocho de febrero de mil novecientos noventa y nueve, al obligar a la persona en contra de quien se prepare el ejercicio de la acción penal siempre y cuando exista el riesgo fundado de que se sustraiga a la acción de la justicia, a permanecer en un domicilio bajo la vigilancia de la autoridad investigadora y persecutora, trae como consecuencia la inmovilidad de su persona en un inmueble, por tanto, es un acto que afecta y restringe la libertad personal que puede ser susceptible de suspensión en términos de lo dispuesto por los artículos 130, 136 y demás relativos de la Ley de Amparo, si para ello se cumplen los requisitos exigidos por la misma ley.
\end{abstract}

Al respecto, se consideró cuál podría ser la mínima molestia y dónde debería estar el individuo sujeto a la vigilancia. Por supuesto, quedó muy en claro que nada mejor que el domicilio de la propia persona sujeto y objeto de la investigación, y así se configuró lo que se entendió, entonces, como arraigo domiciliario; que suponía que la persona llevaría a cabo su vida familiar en su domicilio con una mínima molestia.

Esta condición estaba derivada, precisamente, de la sospecha que hacía que el agente del Ministerio Público no pudiera consignar la averiguación previa y que lo obligaba a hacer una investigación técnica y científica, y a utilizar todas las herramientas que la crimininalística le aportaba, como los dictámenes periciales. Este proceso lo ayudaba a llegar a una conclusión sobre su probable responsable, o bien, descartar la probabilidad de que hubiese participado en la comisión del delito.

Sin embargo, cuando se incorporó en el Código Federal de Procedimientos Penales, el contexto del sistema jurídico mexicano era completamente distinto ${ }^{43}$. En ese momento, el artículo 16 de la Constitución ${ }^{44}$ no

42 Novena época, tomo X, noviembre de 1999. Publicada en el Semanario Judicial de la Federación y en su gaceta, p. 55.

43 Confróntese igualmente AGUILAR LÓPEZ, Miguel Ángel. «El arraigo domiciliario», p. 17.

44 García Ramírez, Sergio. Proceso penal y derechos humanos. México: Porrúa, 1992, p. 255. Dice el autor: «Nuestro CPF emplea, con la mayor frecuencia, sólo la pena de prisión, o bien las penas de prisión y multa en forma conjunta, no alternativa o disyuntiva. Sólo en pocos casos, relativamente, acoge la posibilidad de que sean alternativas: prisión o multa. Esto tiene directa influencia sobre la aplicación de medidas cautelares privativas de libertad. En efecto, no puede dictarse orden de aprehensión o detención a no ser por un 'hecho determinado que la ley castigue con pena corporal', (ahora dice: 'que la ley señale como delito, sancionado cuando menos con pena privativa de libertad'), sostiene el artículo 16 constitucional, y sólo por delito que merezca pena corporal habrá lugar a prisión preventiva dice el artículo 18 constitucional. Una interpretación de ambos preceptos, favorable al reo, también excluye la detención y prisión preventiva en los casos en que la ley señala 
preveía, en forma alguna, la facultad para que el agente del Ministerio Público pudiera detener o retener a alguien por 48 horas $—$ o hasta por 96 horas en el caso de delincuencia organizada- Hasta septiembre de 1993 fue una reforma hecha, precisamente, con el objetivo de ofrecer mayores niveles de seguridad pública y un mejor desempeño de las instancias encargadas de procuración de justicia. Al unirlo a la reforma del artículo 133, bis, del Código Federal de Procedimientos Penales de 1999, se instituyeron dos figuras procesales factibles de decretar dentro de la fase de averiguación previa: el arraigo domiciliario y la prohibición de abandonar la demarcación geográfica; es decir, arraigo territorial o geográfico.

Ese es el contexto en el cual surge el tema de arraigo domiciliario, el que, con el paso del tiempo, se fue transformando. Para 1996 se aprobó aquella fatídica ley denominada Ley Federal contra la Delincuencia Organizada ${ }^{45}$, y en ella se previó un arraigo diverso, porque ya no se aludía al arraigo domiciliario como lo establecen los Códigos de Procedimientos de Penales de Aguascalientes, Baja California, Baja California Sur, Coahuila, Chiapas, Durango, Estado de México, Guanajuato, Guerrero, Hidalgo, Jalisco, Michoacán, Morelos, Nayarit, Nuevo León, Oaxaca, Puebla, Querétaro, San Luis Potosí, Sonora, Tabasco, Tamaulipas, Tlaxcala, Yucatán y Zacatecas.

La situación era distinta en los estados de Campeche, Chihuahua y Quintana Roo, y el Distrito Federal con un esquema similar al del estado de Nayarit y Veracruz, en el cual los delitos de competencia de los jueces de paz admiten el arraigo domiciliario. Esto deja en claro el sentido de una medida precautoria o cautelar y, en su defecto, que el lugar donde será ejecutado es el domicilio. En el caso de San Luis Potosí se reconoce como un beneficio para el caso de delitos culposos; en lugar de decretar la detención o retención, procede el arraigo domiciliario.

El arraigo, que podría llevarse a la práctica en cualquier lugar, entonces iría más allá de la figura originada en el año de 1986, y nos orientaba hacia una nueva dirección que se antojaba ya harto discutible. Esta ley fue tachada de anticonstitucional desde sus propios orígenes y, a la fecha, se sigue discutiendo seriamente la constitucionalidad de la misma; a pesar de existir tesis jurisprudenciales que niegan la inconstitucionalidad de algunos artículos de la propia LFCDO y, en su caso, si se

pena alternativa de corporal y otra que no lo sea: tal ocurre, precisamente, en la disyuntiva entre prisión y multa».

45 Sobre la creación y aplicación de la LFCDO, véase principalmente BRUCCET, Luis Alonso. Delincuencia organizada. México: Porrúa, 2002; y «¿Qué es la delincuencia organizada?». Revista Mexicana de Justicia, sexta época, № 4, México, 2002; García RAmíREZ, Sergio. Delincuencia organizada; antecedentes y regulación penal en México. México: Porrúa, 2002; MoRENo HeRnándeZ, Moisés. "Medidas preventivas contra la delincuencia organizada». Revista Mexicana de Procuración de Justicia, vol. I, №3, octubre, México, 1996; PLASCENCIA ViLlanUeVA, Raúl. Teoría del delito. México: Instituto de Investigaciones Jurídicas/UNAM, 1997, p. 275 y siguientes; ROMÁN PALACIOS, Humberto. «Aspectos adjetivos de la Ley Federal contra la Delincuencia Organizada». Revista Lex. Difusión y análisis, tercera época, año 3, № 27, septiembre, Torreón Coahuila, México, 1997.

MEDIDAS DE

ASEGURAMIENTO Y REFORMA

PENAL: UNA PERSPECTIVA DESDE LOS DERECHOS HUMANOS 
respetan o existe un margen de respeto de los derechos fundamentales de la persona que se encuentra como probable responsable de haber intervenido en la comisión de un delito bajo la modalidad de delincuencia organizada.

El sentido del arraigo no es este, pues no es así como se previó en el sistema de justicia penal mexicano ni con la idea con la que se previó el artículo 16 de la Constitución ni como surgió el arraigo domiciliario. Estas son ideas completamente distintas, pero las reformas que hemos visto y que podemos percibir en los últimos años tienen una orientación muy clara: endurecer el marco jurídico penal. Sobre la base de esta orientación, podemos separar dos aspectos: (1) incrementar las penas; y (2) eliminar, como dice la Conferencia de Procuradores, los obstáculos jurídicos como las garantías individuales y las garantías procesales que limitan la labor de los agentes del Ministerio Público.

Indudablemente, un Estado Democrático de Derecho supone limitar a los servidores públicos en su actuar y la precisión de lo que pueden llevar a cabo, única y exclusivamente. La práctica de un estado autoritario plantea, precisamente, lo contrario ${ }^{46}$; que no existan controles ni límites para el ejercicio del poder, porque esto elimina la eficacia de sus instituciones y su eficiencia.

No obstante, el pasado 19 de septiembre del 2009, la Suprema Corte de Justicia de la Nación consideró que el artículo 122, bis, del Código Procesal Penal del estado de Chihuahua era inconstitucional. La resolución fue votada a favor por ocho ministros, y en consecuencia es una jurisprudencia firme.

\section{IV.7. La participación de la Comisión Nacional de los De- rechos Humanos en la defensa de los derechos fun- damentales del arraigado}

En los últimos años, la Comisión Nacional de los Derechos Humanos ha conocido diversas quejas en las que se señala que el arraigo no se lleva a cabo en el domicilio particular del investigado, menos aun dentro de la determinada demarcación geográfica en la que reside el arraigado, sino que se efectúa en lugares denominados oficialmente «casas de seguridad», en hoteles o en las propias oficinas de las procuradurías de justicia. Esto lleva a considerar que, en la práctica, se traduce en una verdadera privación ilegal de la libertad, donde los indiciados son recluidos en lugares distintos a los señalados por la ley, así como a los permitidos por el orden constitucional.

En cuanto al término del arraigo, como ya se indicó, se ha observado que por regla general la autoridad investigadora solicita de los órganos jurisdiccionales el otorgamiento de la medida cautelar, no solamente por 
el tiempo estrictamente indispensable para la debida integración de la averiguación previa, sino por el término máximo señalado por la ley, con lo que se sujeta al arraigado a permanecer en un determinado lugar durante periodos prolongados, en condiciones que no encuentran justificación en la ley.

Por ello, es necesario que, con el propósito de evitar una violación a los derechos humanos de las personas arraigadas, dicha medida se decrete por el tiempo estrictamente indispensable para la realización de las diligencias de investigación y que el tiempo máximo de detención que permite la ley $\multimap$ bien consignarlo ante la autoridad competente- se reserve exclusivamente para los casos que así lo ameriten. Todo esto si se toma en consideración que, al solicitarse la medida, la actividad ministerial de investigación tiene un objetivo cierto y determinado, y su inactividad se traduce en responsabilidad del servidor o servidores públicos que prolongan la medida sin acreditar la continuación de las investigaciones.

En este sentido, la práctica del arraigo produce diversos efectos colaterales en perjuicio de la persona contra la cual se decreta, pues no solo se suprime su libertad corporal, sino también se le limita su libertad de tránsito y se le obliga a sujetarse a una investigación, durante la cual debe permanecer por un tiempo regularmente prolongado en un lugar, bajo la vigilancia de la autoridad investigadora. Esto trae como consecuencia la inmovilidad de la persona hasta que se resuelva su situación jurídica, y se traduce en un acto que afecta y restringe la libertad personal y, con ello, la violación al derecho de libre tránsito y a los artículos 1 , 11, 14 y 16 de la Constitución Política de los Estados Unidos Mexicanos; 7.1 y 7.2 de la Convención Americana sobre Derechos Humanos y 9.1 y 12.1 del Pacto Internacional de Derechos Civiles y Políticos.

En efecto, la trascendencia a todos los aspectos de la vida de las personas que son sometidas a un arraigo, sobre todo en aquellos casos en los que en razón de la secrecía de las investigaciones, el aislamiento, el detrimento social y económico —al limitar la posibilidad de realizar una actividad remunerada- y, en ocasiones, el hacer público el arraigo, se traducen en un acto arbitrario de la autoridad que lo ejecuta, tal y como ha quedado ilustrado con la tesis jurisprudencial 1a./J., 78/99, emitida por la Primera Sala de la Suprema Corte de Justicia de la Nación: «Arraigo domiciliario, orden de. Afecta la libertad personal» (la cursiva es nuestra).

Por otra parte, en la ejecución del arraigo se ha observado una omisión en el cumplimiento del principio de presunción de inocencia, que impone al agente del Ministerio Público la obligación de dar a todo ser humano sujeto de investigación el tratamiento de inocente hasta que los tribunales competentes, mediante sentencia firme, lo declaren culpable. De lo contrario, se implica la pérdida o la limitación de sus derechos,

MEDIDAS DE ASEGURAMIENTO Y REFORMA PENAL: UNA PERSPECTIVA DESDE LOS DERECHOS HUMANOS 
con lo que se viola uno de los principios fundamentales del Derecho y la justicia, la que se alcanza a través de la seguridad jurídica ${ }^{47}$.

Asimismo, el no considerar la presunción de inocencia en un ser humano sujeto a investigación es un acto que atenta contra su naturaleza y dignidad, con lo que se pone en peligro la realización de sus prerrogativas fundamentales y se impide su ejercicio al ignorar que la seguridad jurídica es la garantía reconocida al individuo para que su persona y sus derechos no sean objeto de ataques violentos, y que si estos llegaran a producirse, deben efectuarse a través de un juicio previo.

Resulta paradójico que una persona que ha sido sentenciada a la privación de su libertad tenga más derechos que aquella contra quien se ha dictado la medida precautoria del arraigo, pues recién se le está investigando y aún no se ha definido su probable responsabilidad penal. Esto, sobre todo, a raíz del nuevo texto incluido en el artículo 18 de la Constitución con motivo de la reforma publicada el 14 de agosto de 2001 que, a la letra, establece: «Los sentenciados en los casos y condiciones que establezca la ley, podrán compurgar sus penas en los centros penitenciaros más cercanos a su domicilio, a fin de propiciar su reintegración a la comunidad como forma de readaptación social».

Lo anterior encuentra fiel reflejo en las quejas recibidas por la Comisión Nacional, en cuyo contenido se pone de manifiesto el desconocimiento del lugar en donde se lleva a cabo el arraigo, el traslado injustificado de personas de un lugar a otro, la carencia de privacidad en las comunicaciones en virtud de la intervención reiterada de las líneas telefónicas y la prohibición de la visita de familiares y abogados, a quienes no se les permite asistir a las diligencias de declaraciones ministeriales de los inculpados ni a nombrar persona de confianza que los asista, lo que provoca una inadecuada y deficiente defensa, en contra de lo previsto por los artículos 14 y 20, fracciones II y IX de la Constitución Política de los Estados Unidos Mexicanos; 8.2., inciso d, de la Convención Americana

47 GonZÁlez-Salas Campos, Raúl. «Principios internacionales del Derecho penal». En Derecho penal. Memoria del congreso internacional de culturas y sistemas jurídicos comparados. I. Derecho penal. México: Instituto de Investigaciones Jurídicas/UNAM, 2005, p. 230 y siguientes. Opina el autor sobre la presunción de inocencia: «[...] esta garantía es la más elemental de entre todas, y está expresamente reconocida sin gravedad ni excepción alguna por la Declaración Universal, el Pacto Internacional, la Declaración Americana y la Convención Americana. Según la interpretación de estos instrumentos, esta garantía se aplica únicamente a procesos penales, aunque la Comisión Interamericana condena la violación de la presunción de inocencia en procesos administrativos cuando la sanción impuesta, como por ejemplo el exilio, se compara con una pena [...]. La cuestión del respeto a la garantía de la presunción de inocencia se plantea en la legislación y en las prácticas de los tribunales nacionales, principalmente en lo que respecta a la prueba. Según la Comisión Interamericana, la presunción de inocencia significa que nadie puede ser condenado por un delito 'mientras no se establezca plenamente su culpabilidad'. De ahí que la Comisión condene como violatoria de la presunción de inocencia la detención y el enjuiciamiento de individuos basándose en 'semi pruebas' de su culpabilidad [...]. El comité de Derechos Humanos, en su comentario general sobre el artículo 14 del Pacto Internacional, observó que 'en virtud de la presunción de inocencia, la carga de la prueba recae sobre la acusación, y el acusado tiene el beneficio de la duda; no puede suponerse a nadie culpable a menos que se haya demostrado la acusación fuera de toda duda razonable'» (subrayado nuestro). 
Sobre Derechos Humanos, y 14.2 del Pacto Internacional de Derechos Civiles y Políticos.

Por consiguiente, esta medida precautoria se traduce en una limitación de los derechos humanos de la persona contra quien se decreta. Y a pesar de que, en la etapa de integración de la averiguación previa en la que se encuentra el indiciado, aún no se haya acreditado su responsabilidad penal; lo que, en consecuencia, no permite que sea objeto de privación o limitación de derechos.

El ejercicio del arraigo trae como consecuencia adicional que la persona contra la cual se ha decretado se encuentre impedida de asistir a sus actividades laborales cotidianas, lo que violenta flagrantemente su derecho al trabajo, sobre todo cuando - al no existir indicios suficientes ni fundados que lo señalen como probable responsable — su detención se basa en simples sospechas.

Por lo anterior, es necesario procurar que la persona sujeta al arraigo pueda trabajar en una actividad lícita, o bien, pueda generar los ingresos necesarios para su subsistencia y la de sus dependientes. La privación de este derecho atenta contra lo dispuesto por los artículos 5 de la Constitución Política de los Estados Unidos Mexicanos; 6.1 del Pacto Internacional de Derechos Económicos, Sociales y Culturales, y 5 del Protocolo Adicional a la Convención Americana sobre Derechos Humanos en Materia de Derechos Económicos, Sociales y Culturales, Protocolo San Salvador, todos los que establecen que el derecho al trabajo solo puede vedarse por determinación judicial, por atacar los derechos de tercero, por resolución gubernativa dictada en términos que marque la ley o cuando se ofendan los derechos de la sociedad.

De igual manera, esta medida precautoria afecta el buen nombre de la persona, que es considerado un derecho subjetivo, puesto que todos los individuos tienen derecho a su propio nombre y a defenderlo contra el uso indebido por terceros. No obstante, no concede a su titular una facultad jurídica de acción, sino solamente una autorización para impedir que una persona interfiera en la esfera jurídica de otra. También existe el deber de respetarlo por él mismo e, incluso, las leyes sancionan su uso indebido.

El derecho al buen nombre está catalogado como un derecho de la personalidad inherente a la calidad humana y, a la vez, los sujetos tienen el deber de ostentar su propio nombre en sus relaciones civiles y públicas en razón del valor de la seguridad jurídica, y para evitar la confusión de personas.

Aun más, debe considerarse que, si bien los individuos tienen derecho a un nombre, también tienen derecho a que este sea respetado, ya que es el reflejo de su buena imagen ante la sociedad. Por ello, resulta contrario a derecho que una persona arraigada sea perjudicada en su imagen. Esta

MEDIDAS DE

ASEGURAMIENTO

Y REFORMA

PENAL: UNA

PERSPECTIVA

DESDE LOS

DERECHOS

HUMANOS 
situación solo genera un clima de condena a su alrededor, sobre todo, en el caso de que se insinúe que la institución tiene elementos suficientes para acreditar supuestos ilícitos.

Finalmente, el indebido manejo de la información que proporcionan las procuradurías a los medios de comunicación respecto de la participación en hechos delictivos de las personas que se encuentran arraigadas y, sin juicio previo, privadas de sus derechos personalísimos ha provocado, en múltiples ocasiones, la aparición de campañas sistemáticas de desprestigio en contra de su honra y reputación. Esto también se traduce en una violación a su derecho a la presunción de inocencia, así como en un atentado en contra del principio de confidencialidad que debe imperar en el orden jurídico mexicano, en beneficio de una adecuada investigación de los delitos.

La principal razón del Estado radica en garantizar a los gobernados la seguridad pública y, con ella, las condiciones que les permitan su pleno desarrollo en un clima de paz y tranquilidad. Pero, en un Estado de Derecho, son precisamente los órganos de éste los primeros obligados a observar las normas que enmarcan su actuar y a respetar los derechos connaturales a los seres humanos, con mayor razón si, como se manifestó en líneas anteriores, aún no existen elementos suficientes para considerar al arraigado como probable responsable.

En esa virtud, es importante destacar que, cuando a la persona contra la cual se decretó el arraigo no le es comprobada responsabilidad en la comisión de ilícito alguno, la medida precautoria le deja secuelas en los órdenes moral, económico y psicológico, y, en consecuencia, una afectación de sus derechos humanos. En este sentido y de conformidad con lo dispuesto por el artículo 9.5 del Pacto Internacional de Derechos Civiles y Políticos, debe ser debidamente indemnizada por los daños que le provocó su ilegal detención. 